\title{
Measurement and Spatial Distribution of Urban Land Use Compactness in Chaoyang District of Beijing, China
}

Min Hong (hongm.07b@igsnrr.ac.cn)

Brian D. Fath (bfath@towson.edu )

\section{Approved by}

Arkady Kryazhimskiy

Leader, Dynamic Systems Programs

December, 2009 


\section{Contents}

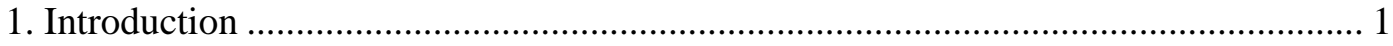

2. Defining Urban Land Use Compactness .................................................................. 3

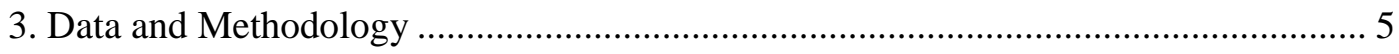

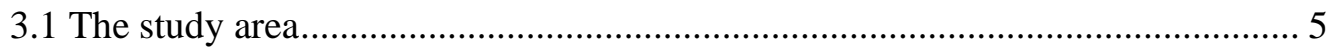

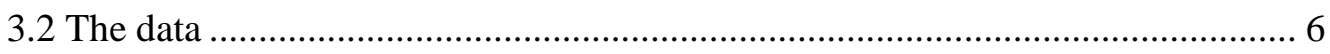

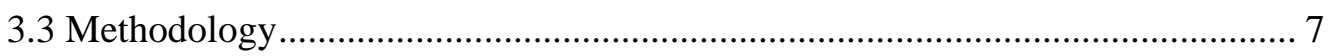

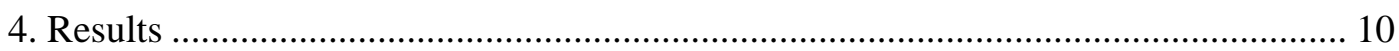

4.1 Comprehensive feature of urban land use compactness ................................ 10

4.2 Spatial distribution characteristics of urban land use compactness................... 11

4.3 Correlation between location and urban land use compactness ....................... 13

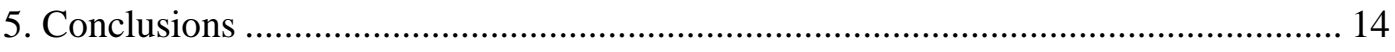

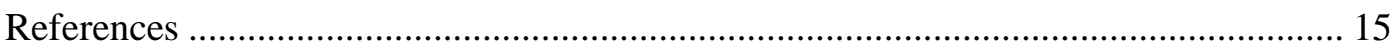




\section{Abstract}

China is in the process of rapid urbanization, and wise land use is critical to the longterm sustainability of Chinese cities. Promotion of a compact city is typically believed to be a helpful for sustainable land use management. However, given the fact that Chinese cities are characterized by high population densities, the applicability of a more compact solution to expanding cities in China remains questionable; there is little evidence to support the many claims in its favor. In seeking to provide empirical data to explore the application of compact city theory in China, one of the key problems researchers face is the task of measuring the urban compactness, in order to objectively investigate the current characteristics of urban compactness.

To meet this need, indices were developed for measuring the urban land use compactness, by which the spatial distribution characteristics of urban land use compactness were identified and applied to the Chaoyang district of Beijing. The following conclusions can be made: (1) Comprehensive land use compactness in Chaoyang district has increased during the period 2001-2007, especially the population density; (2) the spatial distribution of land use compactness has the characteristics of a ring structure, which shows a decreasing trend with its distance to the city center; (3) there is a strong positive correlation between urban land use compactness and location. The better the location is, the higher the land use compactness is

Keywords: Urban land use compactness, measurement indices, Chaoyang district 


\section{Acknowledgments}

The authors would like to thank all the staff in DYN program for their invaluable suggestions on the work presented.

The land use data for Beijing were provided by Beijing Land Resources Management Bureau.

Min Hong's work on this paper was financed by the National Natural Science Foundation of China. 


\section{About the Authors}

Min Hong is a Ph.D candidate at the Institute of Geographical Sciences and Natural Resources Science (IGSNRR), Chinese Academy of Science.

Brian Fath is a Research Scholar at the International Institute for Applied Systems Analysis and an Associate Professor at Towson University working on ecological network analysis and integrated modeling. 


\section{Measurement and Spatial Distribution of Urban Land Use Compactness in Chaoyang District of Beijing, China}

Min Hong

Brian D. Fath 


\section{Introduction}

The future form of cities and the role of land use planning in guiding their development are of particular concern for policy makers at inter-governmental, national government and local government levels (Jenks et al., 1996). This debate on urban form has intensified since the early 1990s, particularly after the Commission of European Communities (CEC) published their "Green Paper on the Urban environment" (1990) (Morrison, 1998). The concept of a compact city has been proposed as a sustainable urban form by the CEC, which can save resources and energy, and revitalize an inner city, etc. Since then, promotion of the compact city approach has been enshrined in land-use planning policy in developed countries (mostly in Europe). In Britain, compact city policy focused on redeveloping existing buildings at higher densities and increasing the "activity density" of buildings through programs such as "living above the shop" to ensure a more efficient use of existing buildings (Williams et. al. 1996). Moreover, the British central government developed an urban development policy clearly favoring urban intensification, in the report Sustainable Development: The UK Strategy, which states: 'The Government's objective for 2012 is to continue to make the best use of the land resource by maximizing the use for development of urban land, especially where it is vacant, derelict or contaminated land, and protecting the open countryside and open land of importance in urban areas’ (cited in Williams et. al., 1996: 85).

As identified above, the compact city policy was fairly well developed and implemented in Britain. However, there is little literature considering the implementation of compact city policy in developing countries, where more than twothirds of worlds' population is settled. In the meantime, most cities in developing countries are characterized by high population densities, the applicability of a more compact solution to these cities remains questionable; there is little evidence to support the many claims in its favor. In seeking to provide empirical data to explore the 
application of compact city theory in developing countries, one of the key problems researchers face is the task of measuring the urban compactness, which the current characteristic of urban compactness can be investigated clearly.

At present, urban researchers have been increasing efforts to study and measure urban compactness. Burton (2002) first developed a set of indicators to measure urban compactness in UK towns and cities. In her research, a compact city has been described according to three classifications: high-density city, mixed-use city, and intensified city. Large sets of indicators have been developed for demonstrating compactness variables (details refer to Burton, 2002). Tsai (2005) proposed four quantitative variables to measure urban form at the metropolitan level, and found out that the global Moran coefficient can distinguish compactness from sprawl through a series of simulation analyses with global Moran, Geary, and Gini coefficients. Turskis (2006) evaluated and calculated the rate of urban compactness with GIS and Bayesian rules. Five indicators were proposed to evaluate factors of population density, evenness of population distribution, population proximity to working places, population proximity to public amenities, and density of public transport network. Fang and Qi (2008) proposed the definition of urban agglomerations compactness and divided it into three aspects: urban agglomeration industry compactness, urban agglomeration spatial compactness, and urban agglomeration traffic compactness. From these studies, one sees that measuring urban compactness focused on the total city or between cities. There is little literature to study spatial distribution characteristics of urban inner compactness from the perspective of land use. In the meantime, some indicators above may not be appropriate for Chinese cities as they were proposed for the urbanization of western countries. And, some indicators cannot be used because of the data shortage such as employment density indicator. Therefore, this study attempts to investigate a city's spatial, internal distribution from the perspective of land use through adopting the measurement indices of land use compactness. 
China is in the process of rapid urbanization and land saving is critical to the longterm sustainability of Chinese cities. Promotion of compact city is helpful for the land use sustainability (Chen et al., 2008). Thus, Chaoyang district, the largest and most densely populated urban district of Beijing City, was chosen as study area, which urban compactness has not yet been empirically measured or characterized. Investigating this spatial phenomenon in this district with a limited land resource, but a relatively high population density, in contrast to the situation in most other European cities, may lead to new insights about the phenomenon. On the more practical level, measuring compactness in the Chaoyang district is crucial to the better management of its land resources.

Thus, this paper is organized as follows. Section 2 gives working definitions of urban land use compactness with relevant literature references. Section 3 briefly introduces the study area, data and methods. The measurement results are presented and analyzed in Section 4. Section 5 summarizes the findings of this study.

\section{Defining Urban Land Use Compactness}

Until recently there was not a clear, accurate, and quantitative definition of urban compactness because current research focuses more broadly on the sustainable development debate and the consequent translation into policy and practice at the local national and international levels. Therefore, definitions for the research were developed in line with understanding of the concept within this context (Burton, 2002).

The most common definition of compactness was given by Breheny (1997), who concluded that a compact city typically promotes urban regeneration, the revitalization of town centers, restraint on development in rural areas, higher densities, mixed use development, promotion of public transport, and the concentration of urban development at public transport nodes. A “Green Paper on the Urban Environment” 
which was published by the Commission of European Communities (CEC,1990) proposed that "compact city" would be modeled on "the old traditional life of the European City, stressing density, multiple use, social and cultural diversity” (Morrison,1998). The proposal of the "compact city" concept was to avoid the continuous extension of city boundaries escaping from the current cities' problems, and tried to be resolved within the boundaries of existing urban problems (Thomas et al., 2004). Ewing (1997) considered that the meaning of compact is the aggregation of work and residential place including the mixed-use of land function. Anderson et al. (1996) considered that monocentric and polycentric city form both can be thought as compact form. Burton (2002) identified the compact city into three aspects: a high-density city, a mixed-use city and an intensified city. Gordon and Richardson (1997) defined compactness as a spatial pattern oriented downtown or central city with high density.

From the above definitions, we can find that compactness was defined from urban patterns, characteristics, and functions, etc. This paper summarizes the conceptual definition of compactness based on three dimensions of land use pattern: spatial carrying capacity, spatial function, and spatial form. Compactness of spatial carrying capacity means high density of population and built-up land which is seen to be an essential component of a compact city. It is claimed that high residential densities may reduce car travel by increasing the range of opportunities that can be accessed within convenient walking or mass transit time (Burton, 2002). Compactness of spatial function refers to mix land use which the city can be a functional organism through different city function elements' interaction and interrelation. It is claimed that mixed land use may reduce commuting by increasing the functions' interaction and interrelation. Spatial form compactness refers to adopting the suitable land use pattern which can fit for urban scales. It is claimed that monocentric and polycentric city form both can be thought as compact form (Anderson et al., 1996). Thus, the next 
measurement indicator systems of land use compactness are based on the defining of land use compactness (see Table 1).

\section{Data and Methodology}

\subsection{The study area}

Chaoyang District is the largest and most densely populated urban district of Beijing City (see Fig1) (http://bci.bjchy.gov.cn/chaoyang). It is located in east Beijing and covers $470.6 \mathrm{~km}^{2}$, extending $28 \mathrm{~km}$ from south to north and $17 \mathrm{~km}$ from east to west. The resident population is 2.585 million, 1.657 million of whom are permanent residents (64\%). The district encompasses all types of industries and in 2000 it ranked among Beijing's advanced urban districts and counties in terms of aggregate assets (900 billion yuan).

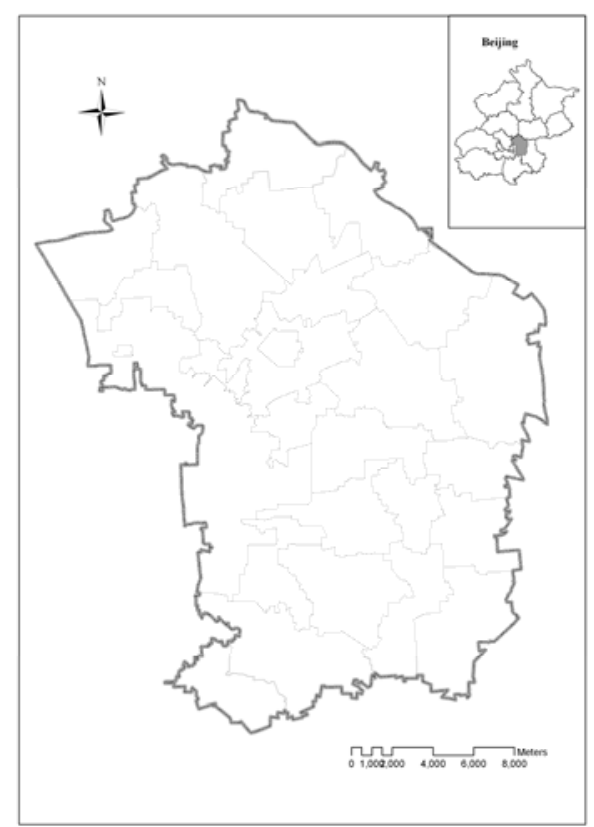

Fig 1.The study area in Chaoyang District of Beijing, China 


\subsection{The data}

Data sources include digitized land use maps stored in a GIS file as well as selected statistical data.

(1) Land use map

Land use maps were available for the years 2001 and 2007 in vector format from Beijing Land Resources Bureau. The land use map in 2001 is the result of a detailed land use survey, and the land use map in 2007 is the result of an annual updating survey. Since land use categories were changed during 2001 and 2007, we reclassified them into eight comparable types based on the new category system as follows:

1) farmland (including irrigated - dry land and vegetable plots etc.),

2) pasture land (including all kinds of the garden)

3) forest land (including trees, shrubs and nursery garden etc.),

4) water bodies (including river and pod etc.),

5) residential areas

6) industrial areas

7) transportation corridors (main roads).

8) uncultivated land

(2) Digitized version of the transportation map

A digitized version of the transportation map was derived from a hardcopy of Beijing transportation map published by China Map Press. And we only selected the highways, ring roads and outward transportation lines from that transportation map for analysis in this paper. 
(3) Other statistical data

Population and GDP statistical data are from the Statistical Yearbook, including total population and its subcategories, urban population and rural population from 2001 to 2007.

\subsection{Methodology}

Based on literature review we selected indicators for measuring urban land use compactness. In addition, we use the following methods to compute compact indices and explore spatial distribution characteristics of urban land use compactness.

\subsubsection{Measurement indicators}

According to compact city theory, the land use compactness can be divided into three dimensions (spatial carrying capacity, spatial function, and spatial form). Each dimension can be expressed by several indices. We also define the direction of each measure on the level of compactness (see Table 1).

Table 1. Measurement indicator systems of urban land use compactness

\begin{tabular}{ccc}
\hline $\begin{array}{c}\text { Conceptual dimensions of } \\
\text { compactness }\end{array}$ & Variables & $\begin{array}{c}\text { Directions of impact on } \\
\text { level of compactness }\end{array}$ \\
\hline Spatial carrying capacity & Population density & $(+)$ \\
Spatial function & Built-up land density & $(+)$ \\
& Simpson diversity index & $(+)$ \\
Spatial form & Fragmentation index & $(-)$ \\
& Fractal dimension & $(+)$
\end{tabular}


(1) population density

$$
P D I=P_{\mathrm{j}} / A_{\mathrm{j}}
$$

Where $P_{\mathrm{j}}$ is the population of the area, and, $A_{\mathrm{j}}$ is the area of the built-up land.

Relatively high population density means compactness, whereas low population density means sprawl.

(2) Built-up land density

$$
H D I=\mathrm{Nb}_{\mathrm{i}} / N_{i}
$$

Where $N b_{i}$ is the pixel numbers of built-up land in the neighborhood and $N_{i}$ is the total numbers of pixel in the neighborhood.

(3) Simpson's diversity index

$$
H=1-\sum_{\mathrm{i}=1}^{N}\left(\frac{A_{\mathrm{i}}}{T A}\right)^{2}
$$

Where $A^{i}$ is the area of land use type $i, T A$ is the total area of land use.

(4) Fragmentation index

$$
F=[(N-1) / C] \times 100 \%
$$

Where $N$ is the total numbers of every kind of patches, $C$ is the ratio of total areas and the smallest patch area. High $F$ value means high mix land use. 
(5) fractal dimension (Dong, 1991)

$$
\ln [A(r)]=\frac{2}{D} \ln P(r)+C
$$

Where $A(r)$ is the area of land use patch, $P(r)$ is the perimeter of land use patch, $C$ is constant, $D$ is the fractal dimension.

(6) compactness index (Xia and Gar-On Yeh, 2004)

$$
C I=\frac{\sum_{\mathrm{j}} P_{\mathrm{j}} / \mathrm{p}_{\mathrm{j}}}{\mathrm{n}}=\frac{\sum_{\mathrm{j}} 2 \sqrt{\left(S_{j} / \pi\right) / p_{j}}}{n}
$$

Where $C I$ is compactness index, $S_{\mathrm{j}}$ is the area of land use patch, $\mathrm{p}_{\mathrm{j}}$ is the perimeter of land use patch, $n$ is the total numbers of all patches. High compactness index value means high compactness of land use form.

\subsubsection{GIS spatial analysis}

GIS spatial analysis methods such as neighborhood analysis were used to compute the indices to identify the existence of urban land use compactness. And by the method of kriging interpolation and buffer analysis, distribution maps of urban land use compactness can be generated in order to explore the distribution characteristics of urban land use compactness.

\subsubsection{Landscape analysis}

Landscape indices such as Simpson diversity index were chosen as indices for measuring urban land use compactness in order to capture the characteristics of urban compactness. 


\section{Results}

\subsection{Comprehensive feature of urban land use compactness}

Land use compactness in Chaoyang district has increased between 2001 and 2007. The results of the calculations are listed in Table 2. From the spatial carrying capacity dimension, we can find that net population density in Chaoyang district has increased rapidly during this seven year period, from 5,858 to 11,314person $/ \mathrm{km}^{2}$. The built-up land density also increased, but not so obviously. This phenomenon indicates that the land use intensity has improved during these seven years, in that the population in Chaoyang district grew more quickly than the built-up land area. The fractal dimension and compactness index were chosen to identify urban land use compactness from the exterior form of urban land use. As Table 2 shows, the fractal dimension diminished from 1.1110 to 1.0933 , which means land use pattern in 2007 has become more compact than 2001. The calculation results of compactness index indicate the same trend. The two functional indices results both increase showing that built-up land became more mixed.

Table 2. Calculating results of urban land use compactness in Chaoyang district of Beijing, China

\begin{tabular}{cccc}
\hline $\begin{array}{c}\text { Conceptual dimension } \\
\text { of compactness }\end{array}$ & indices & 2001 & 2007 \\
\hline $\begin{array}{c}\text { Spatial carrying } \\
\text { capacity }\end{array}$ & Net population density & 5858 & 11314 \\
& Built-up land density & 0.5822 & 0.5829 \\
Spatial form & Fractal dimension & 1.0933 \\
& Compactness index & 0.2357 & 0.2387 \\
Spatial function & Simpson diversity index & 0.9967 & 0.9976 \\
& & & 0.1494 \\
& Fragmentation index & 0.0959 & \\
\cline { 2 - 4 }
\end{tabular}




\subsection{Spatial distribution characteristics of urban land use compactness}

\subsubsection{Population density}

The digital model of population in the study area of Chaoyang district from 2001 to 2007 was generated by land use density, on which the county's population data were transferred to the data based on the built-up land. Figure 2 presents the distribution of population density in two periods. We found that the population is highly aggregated within the $3^{\text {rd }}$ ring road, which the population density is about 25000 people per $\mathrm{km}^{2}$. Outside the $3^{\text {rd }}$ ring road, it decreased quickly to a population density of around 6000 people per $\mathrm{km}^{2}$. As the figure comparing the time periods shows, the population density increased between the $3^{\text {rd }}$ and $4^{\text {th }}$ ring road, but not so obviously. Lastly, we can also find that the population density decreased within the $3^{\text {rd }}$ ring road in seven years.

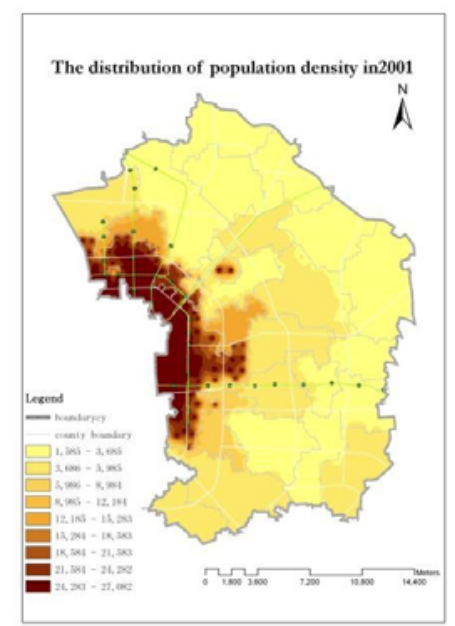

(a)

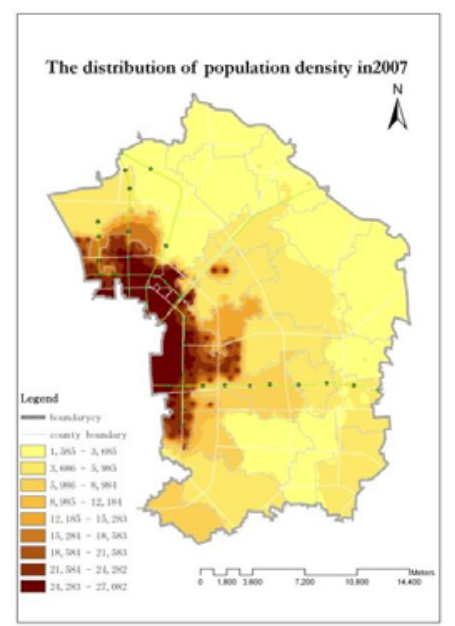

(b)

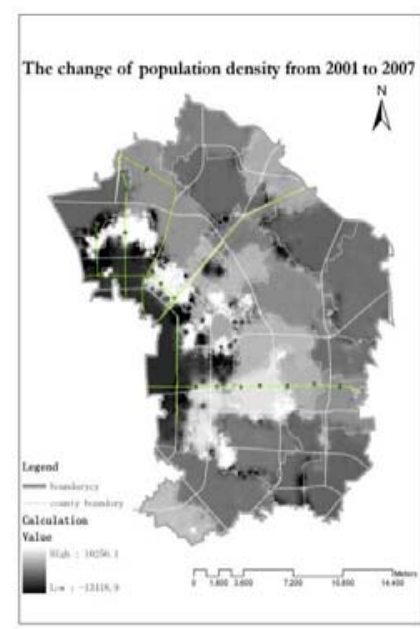

(c)

Fig 2. The distribution of population density in 2001 (a), 2007 (b), the change from 2001 to 2007 (c) 


\subsubsection{Built-up land density}

The distribution maps of built-up density in Chaoyang district from 2001 and 2007 were generated with the method of neighborhood analysis. The computation of built-up land density gave the distribution of the high, medium and low-density built-up clusters in the study area. High built-up density refers to areas with clustered or more compact development, while medium density refers to relatively lesser compact development and low density refers to loosely or sparsely spread built-up areas. Figure 3 reveals that the more compact or highly dense built-up land composed the smallest fraction of land cover, and low-density was the largest cover type. An important finding that could be drawn out of this was that high and medium density was found all along with the county centers. Most of the high density was found to be within and closer to the cities centers particularly, near transit hubs. However, low density was also found mostly along the city periphery.

We also can find that the density of built-up land decreased with distance from city center. As Figure 3c shows, the built-up land density showed an outward expansion trend and the area outside the $4^{\text {th }}$ ring road increased more significantly. But it was still largely in medium - low density. This phenomenon indicates that the compactness of built-up land in Chaoyang district has increased from 2001 to 2007, but the compactness of land use is not so high. 


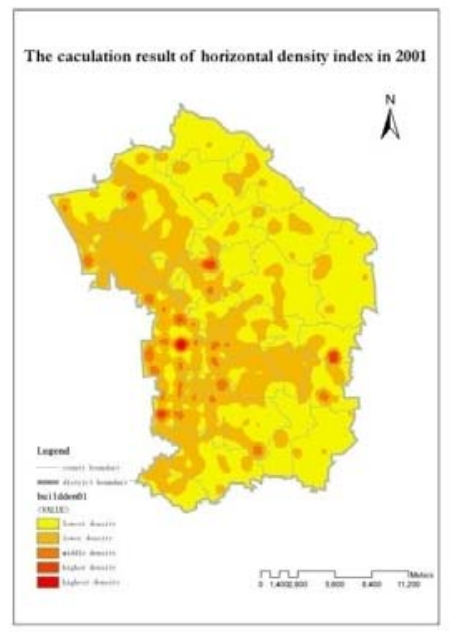

(a)

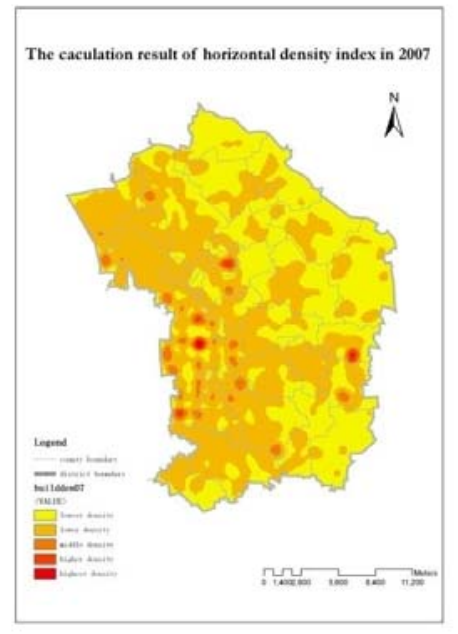

(b)

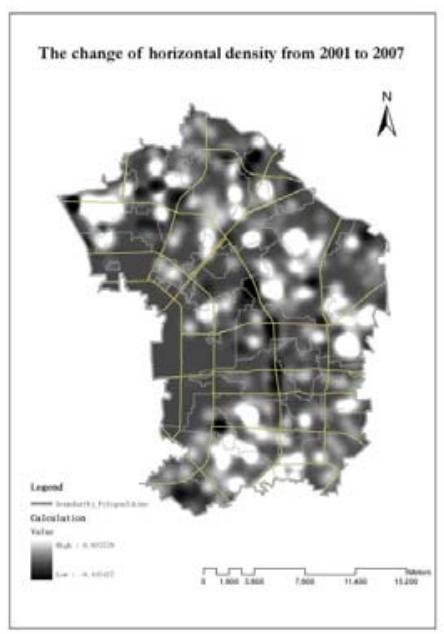

(c)

Fig 3. The distribution of horizontal density in 2001 (a), 2007 (b), the change from 2001 to 2007 (c)

\subsection{Correlation between location and urban land use compactness}

In order to examine the relationship between location and its compactness level, we choose the net population index as a compactness level variable to explore the dynamic mechanism. Circle buffer analysis method was used to identify the location mechanism influencing compactness. The circle buffers were drawn with the center of Beijing city and the circle interval was equally $1 \mathrm{~km}$ (see Figure 4). The figure presents the change of net population density with the distance from the city center between 2001 and 2007 showing a decrease in population density with distance from the city centre. 


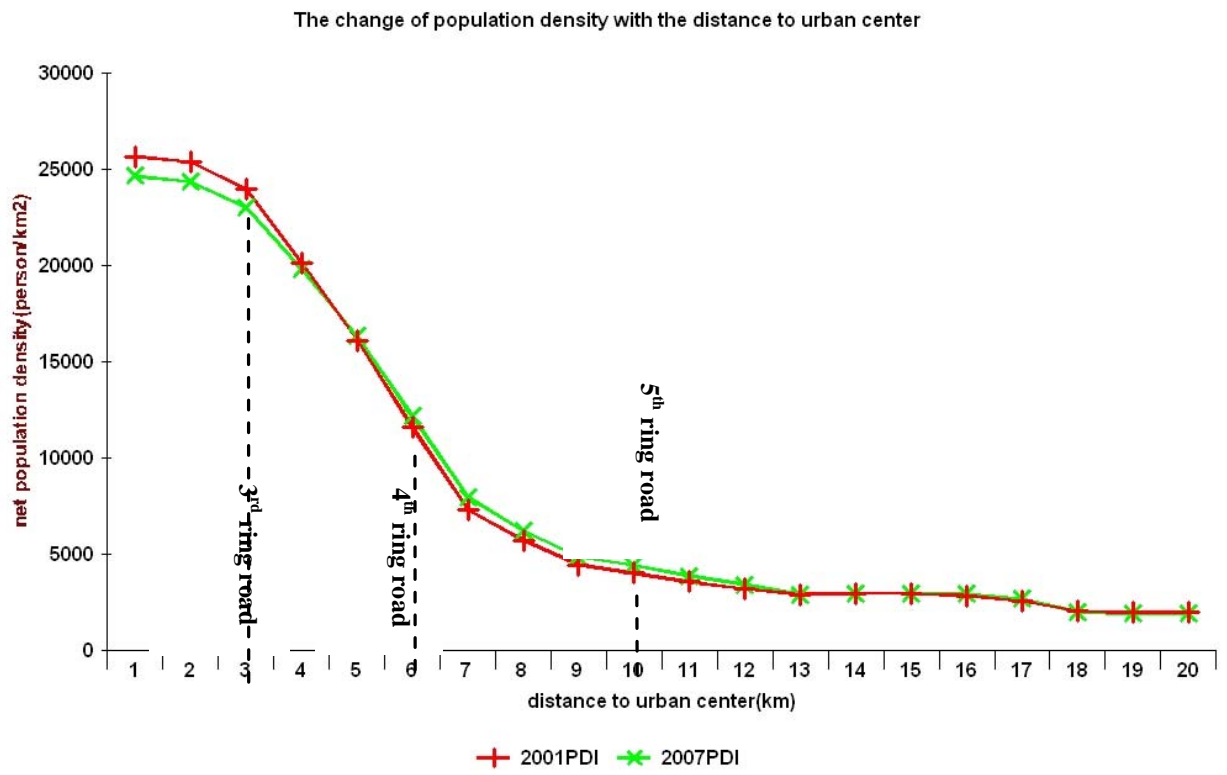

Fig 4. The change of population density with the distance to city centre from 2001 to 2007

\section{Conclusions}

This study examines land use compactness in Chaoyang District of Beijing from 2001 to 2007, with the data at county level. The main conclusions are as follows.

(1) Comprehensive land use compactness in Chaoyang district has increased during seven years, especially the population density.

(2)The spatial distribution of land use compactness has the characteristics of ring structure, which shows decreasing trend with its distance from the city center.

(3) There is remarkable positive correlation between urban land use compactness and location. The better the location is, the higher the land use compactness is. 
Overall, these results are consistent with other findings regarding compact city development. Chaoyang District's population is growing faster than the built-up area resulting in greater density, although the outer areas are nowhere near as dense as the inner core. In fact, the inner core actually saw a decrease in density during the period from 2001 to 2007 . Further research is needed to determine if the trend toward greater compactness had measurable environmental or social benefits.

\section{References}

1. Anderson, W. P., Kanaroglou, P. S., and Miller, E. J. Urban form, energy and the environment: a review of issues, evidence and policy, Urban Studies. 1996, 33(1): 7-35.

2. Breheny, M . Urban compaction: feasible and acceptable? Cities. 1997, 14(4), 209217.

3. Burton, E. Measuring urban compactness in UK towns and cities. Environment and planning B: Planning and Design. 2002, 29:219-250.

4. Chen, H., Jia, B., and Lau, S.S.Y. Sustainable urban form for Chinese compact cities: Challenges of a rapid urbanized economy. Habitat International. 2008, 32: 28-40.

5. Dong, L. Fractal theory and its application. Shenyang: Science Press in Liaoyang. 1991: 5-30.

6. Ewing, R. Is Los Angeles-style sprawl desirable? Journal of the American Planning Association. 1997, 63(1): 107-126

7. Fang, C., Qi, W. Researches on comprehensive measurement of compactness of urban agglomerations in China. Acta Geographica Sinica. 2008, 63(10): 1011-1021.

8. Gordon, P., Richardson, H. W. Are compact cities a desirable planning goal? Journal of the American Planning Association. 1997, 63(1): 95-106.

9. Jenks, A., Burton E., and Williams, K. Compact City: A Sustainable Urban Form? 1996, London, E. \& F.N. Spon. 
10. Morrison, N. The compact city: Theory versus Practice - The Case of Cambridge Neth. J. of Housing and the Built Environment, 1998 (13) : 2.

11. Thomas, L., and Will, C. A successful, appropriate and feasibility urban form?' in Jenks, M., Burton, E. and Williams, K. (eds.) The Compact City: a sustainable urban form? China Architecture \& Building Press. 2004:57-69"

12. Tsai, Y-H. Quantifying urban form: Compactness versus Sprawl. Urban Studies, 2005, 42(1): 141-161.

13. Turskis, Z. Sustainable city compactness evaluation on the basis of GIS and Bayes rule. International Journal of Strategic Property Management 2006, 10:185-207.

14. Williams, K., Burton, E., and Jenks, M. (1996) 'Achieving the Compact City through Intensification: an acceptable option?' in Jenks, M., Burton, E. and Williams, K. (eds.) The Compact City: a sustainable urban form? London, E. \& F.N. Spon, 83-96.

15. Xia, L., and Gar-On Yeh, A. Analyzing spatial restructuring of land use patterns in a fast growing region using remote sensing and GIS. Landscape and Urban Planning 2004, 69: 335-354. 